\title{
Scapular Island Flap as a Workhorse Flap for Axillary Defect Reconstruction
}

\section{Aksiller Defekt Onarımının Ana Flebi Olarak Skapüler Ada Flebi}

Mehmet Altiparmak ${ }^{1}$,

${ }^{1}$ Muğla Sıtkı Koçman University, Faculty of Medicine, Department of Plastic,

Recontructive and Aesthetic Surgery, Muğla, Turkey

Geliş Tarihi/Received: 08 February 2020 Kabul Tarihi/Accepted: 01 March 2020

Address correspondence to: Mehmet Altiparmak, Muğla Sıtkı Koçman University, Faculty of Medicine,

Department of Plastic, Recontructive and Aesthetic Surgery, Muğla/TURKEY

e-posta: dr.maltiparmak@gmail.com

ORCID

Mehmet Altiparmak

https://orcid.org/0000-0002-9971-7137

\section{INTRODUCTION}

Axillary defects mostly occur after burn contracture releases or hidradenitis suppurativa debridements.
Generally a dome shaped defect with a superficial neurovascular structure is exposed. Reconstruction of this type of defect is a challenge since the ultimate

Cite this article as: Altiparmak M. Scapular Island Flap as a Workhorse

Flap for Axillary Defect Reconstruction. Selcuk Med J 2020;36(1): 39-43 
aim is maintaining a pliable coverage with full mobility of the shoulder joint. Skin grafts (1), local flaps $(2,3)$ and free flaps $(4,5)$ were used to cover the deep and mobile defect of the axilla. Well-vascularized, thin, flexible and contracture free coverage should be aimed in selecting the ideal technique in axillary defect coverage.

Scapular flap is one of the reconstructive options in axillary defect coverage. The horizontal branch of circumflex scapular artery is the nutrient vessel of the flap. Scapular flap could be executed as a local flap(6) or a free flap(7) or even as a pre-expanded flap(8) according to the requirements. It is best known with the thin and pliable skin that is an ideal structure for the axilla. However, there is no straightforward answer to which flap is the ideal choice of axillary coverage. This study is aiming to present reconstruction of axillary defects with scapular island flaps for different indications and to discuss the outcomes of the donor sites so as to suggest it as a workhorse flap in axillary
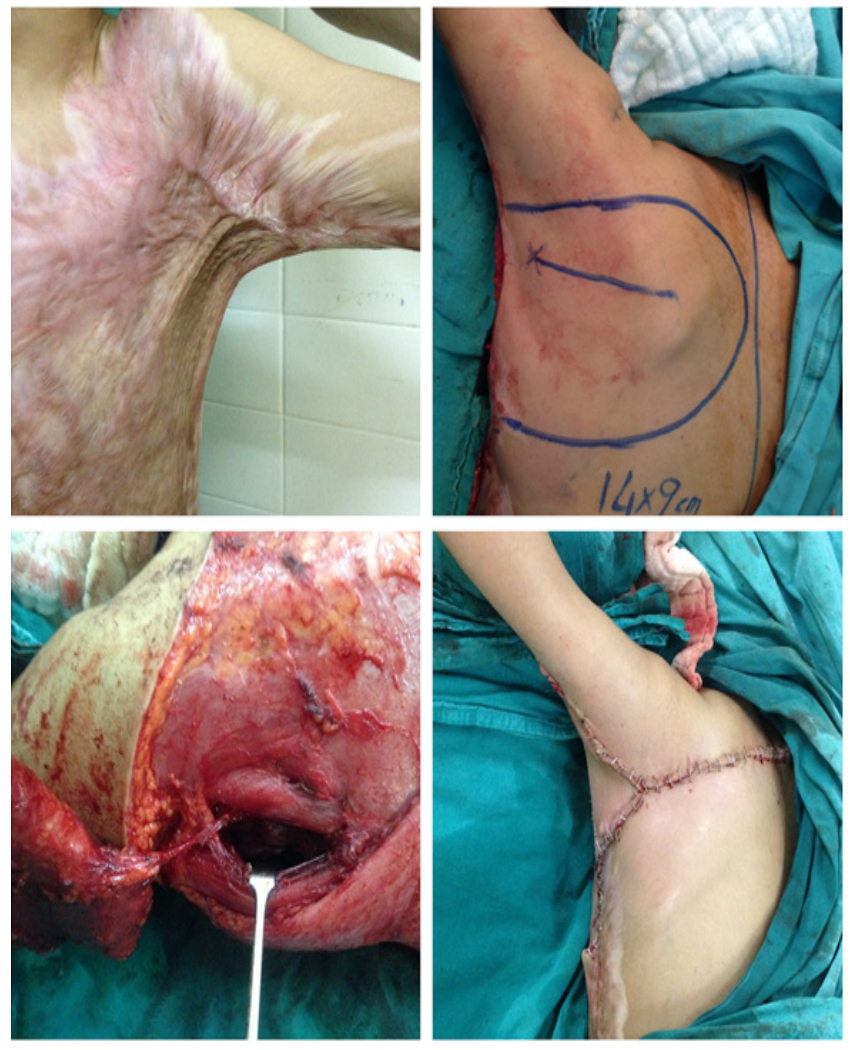

Figure 1. Technique of scapular flap elevation. Above Left: Axillary contracture extending to the arm and posterior axillary line. Above Right: Planning of the scapular flap in a prone position. Below Left: Skeletonizing the pedicle and dissection of the triangular space. Below Right: Coverage of the defect without any tension

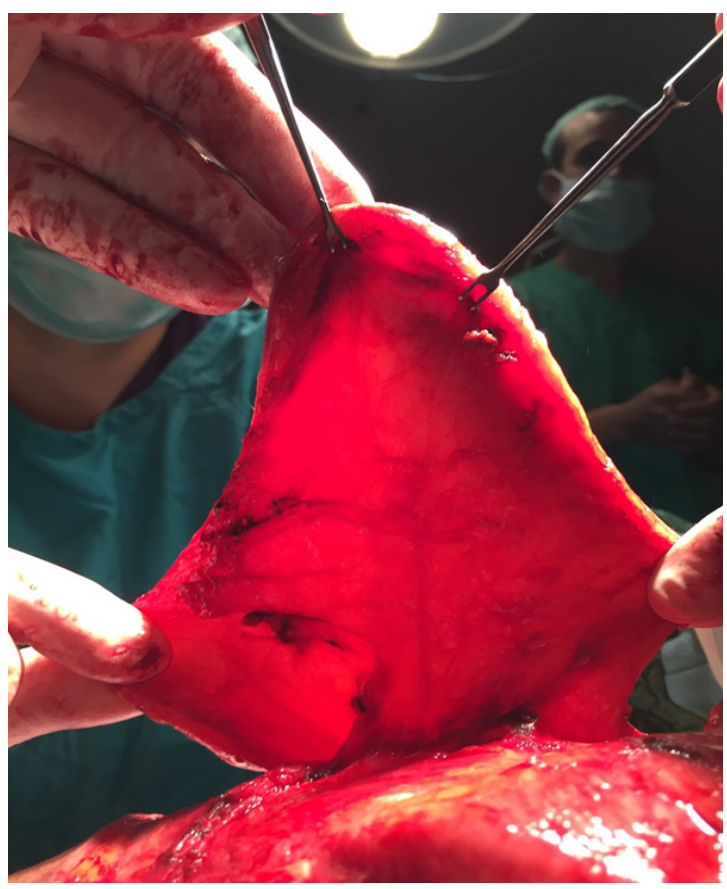

Figure 2. Transillumination of the pedicle.

reconstruction.

\section{PATIENTS AND METHODS}

A total of 7 patients treated with 8 scapular island flaps between 2015 and 2019 were included retrospectively. Five patients were operated for hidradenitis suppurativa and 2 patients reconstructed for axillary contracture. Cefazolin was administered to all patients prior to surgery and until post-operative day 1 . Patients received physical therapy 3 weeks after the operation in order to restore shoulder function.

\section{Operative Technique:}

Patients are prepared in a lateral decubitus or a prone position after adequate debridement of contracture/hidradenitis suppurativa. The arm, if possible, is placed in 90 degrees of abduction so as to create an obtuse angle of the functioning shoulder. Defect size is measured and circumflex scapular artery could be marked with a handheld doppler. Horizontal extension of the flap is drawn over the scapula with a width no more than $12 \mathrm{~cm}$ in order to maintain primary closure. Flap length should not exceed the midline of the back since this may cause tip necrosis. Elevation starts from the distal part of the flap above the deep fascia. The flap could easily 
Table 1. Demographics of patients reconstructed with scapular island flaps

\begin{tabular}{|c|c|c|c|c|c|c|}
\hline$\overline{\text { Case }}$ & Age (year) & Gender & Etiology & Axillary side & Flap dimension $(\mathrm{cm})$ & Outcome \\
\hline 1 & 8 & Male & Burn contracture & Left & $14 \times 9$ & $\begin{array}{l}\text { Good contour } \\
\text { and ROM }\end{array}$ \\
\hline 2 & 36 & Female & HS & Left & $16 \times 9$ & Good contour \\
\hline 3 & 46 & Male & HS & Left & $18 \times 9$ & Good contour \\
\hline 4 & 52 & Male & HS & Bilateral & $\begin{array}{l}15 \times 8 \text { (left) } \\
15 \times 9 \text { (right) }\end{array}$ & $\begin{array}{l}\text { Good contour } \\
\text { d no recurrences }\end{array}$ \\
\hline 5 & 2 & Female & Burn contracture & Right & $14 \times 8$ & $\begin{array}{l}\text { Tip necrosis, } \\
\text { econdary healing }\end{array}$ \\
\hline 6 & 23 & Female & HS & Right & $13 \times 8$ & Good contour \\
\hline 7 & 48 & Male & HS & Right & $15 \times 8$ & Good contour \\
\hline
\end{tabular}

HS: Hidradenitis suppurativa, ROM: Range of motion

be elevated until the posterior axillary fold where the circumflex scapular artery gives its horizontal branch. Superior and inferior incisions are completed at the most lateral point and the pedicle is skeletonized. The triangular space is dissected and the scapular island flap is gently pulled through it. Scapular flap execution on an axillary contracture is demonstrated in Figure 1. Transillumination may be beneficial to observe the pedicle within the flap (Figure 2). This maneuver gives extra length to the pedicle without any risk of kinking. The flap is inserted on the defect and the donor site is

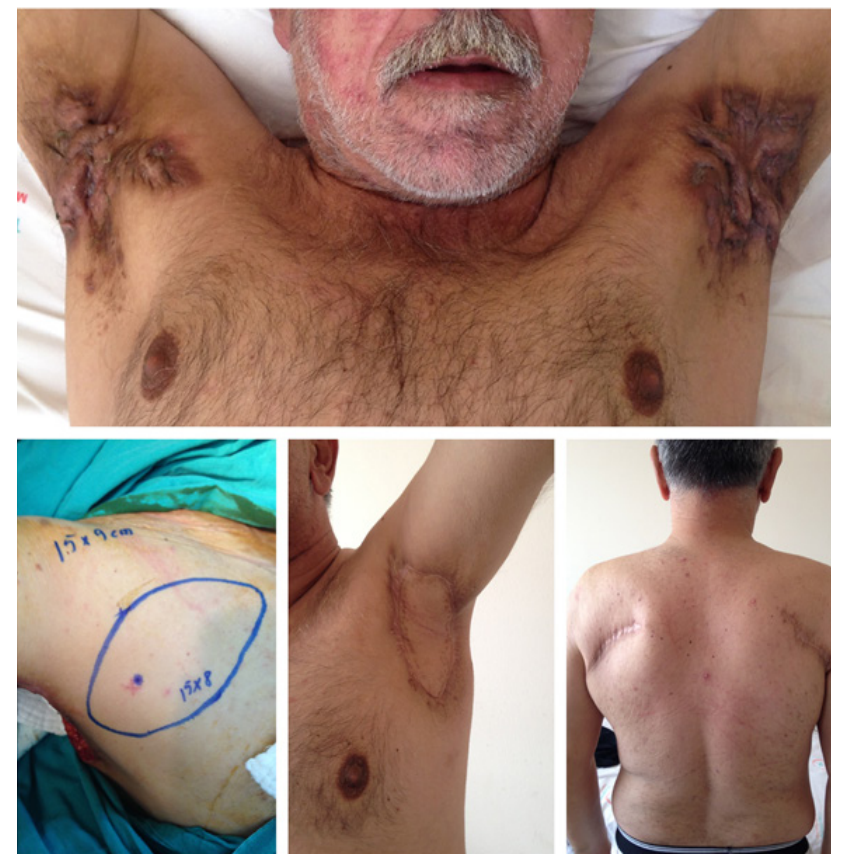

Figure 3. Above: Bilateral hidradenitis suppurativa case. Below Left: Detection of the pedicle and preoperative drawing. Below Center: Left axillary defect coverage. Below Right: Bilateral scapular flap scarring. closed primarily. It is beneficial to insert a drain under the flap far from the pedicle.

\section{RESULTS}

All flaps survived without any major complications except one flap that had wound margin dehiscence which healed in secondary intention. This minor complication occurred in a 2 year old patient with excessive burn areas on the extremity. All patients healed with free shoulder functions after at least 6 months of follow-ups. Flap dimensions ranged from $84 \mathrm{~cm} 2$ to $128 \mathrm{~cm} 2$ without exceeding $9 \mathrm{~cm}$ of the
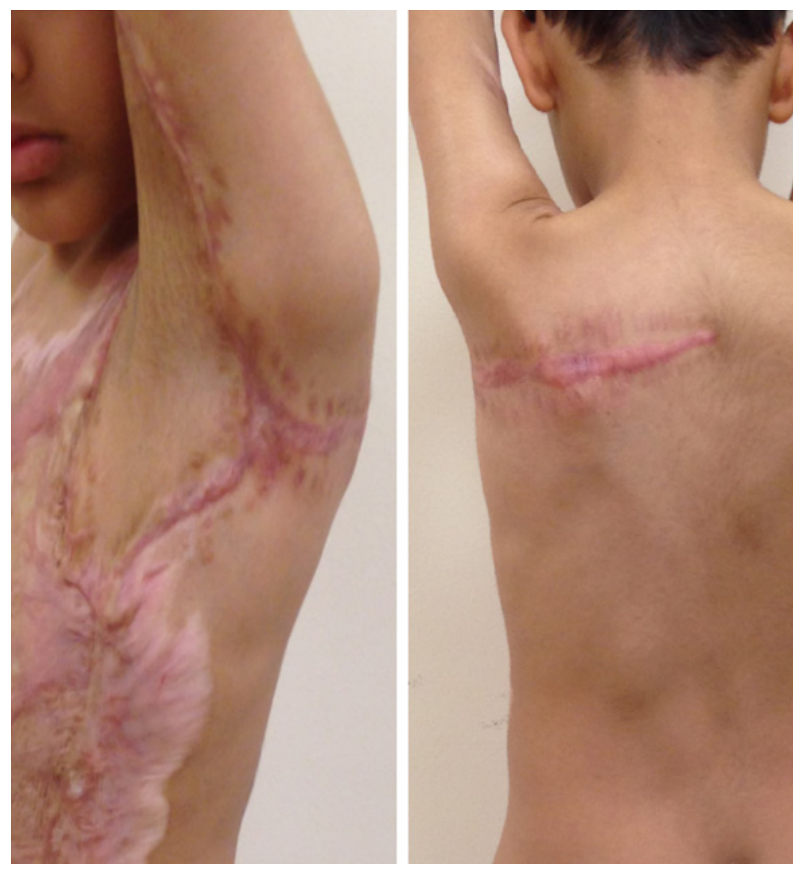

Figure 4. Postoperative 6 months of the patient in Figure 1. Note the widening of the scars. 


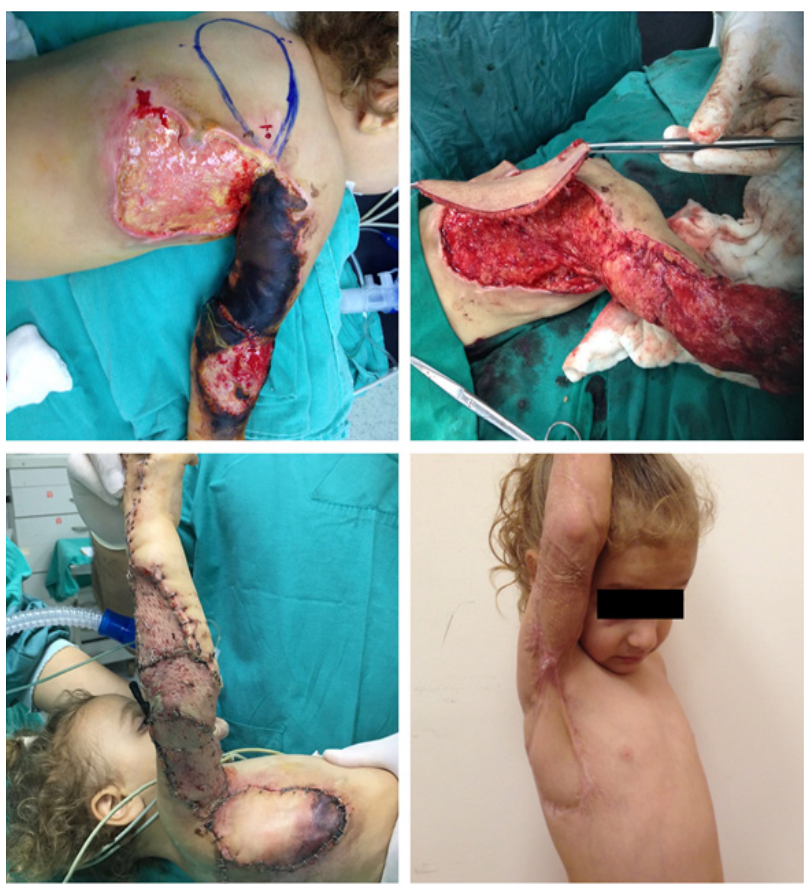

Figure 5. Presentation of Case 5. Above Left: Severe burn injury on the arm and lateral torso. Above Right: Extensive debridement and elevation of the flap. Skeletonizing the pedicle could be harder in pediatric patients. Below Left: Forearm and arm defects were grafted. Axilla and lateral torso is covered with scapular flap. Below Right: Axillary and arm range of motion is acceptable. Nipple-areolar complex is on the midline.

width. Donor site scars widened between 3 months to 6 months post-operatively and independent of patient age. Donor site scars ranged from $1.5-2.6 \mathrm{~cm}$. Figure numbers 3 and 4 demonstrate hidradenitis suppurativa and burn contracture treatments with scapular island flaps respectively. Keloids were not observed.

Case 1:

An 8 years old patient with a severe burn contracture on the left side axillary region. This patient had a history of flame burn injury 2 years prior to initial referral to our clinic. Approximately $27 \%$ of total body burn surface area was calculated. He had left axillary and perineal contractures. The patient received a left side axillary contracture release and scapular artery island flap reconstruction. Three months after this operation, scar contractures on the perineum were treated with multiple z-plasties. The patiens had good range of motion in the follow-ups. Axillary contracture, intraoperative and post-operative images are demonstrated in Figures 1, 2 and 4.

\section{Case 4:}

A 52 years old patient with hidradenitis suppurativa in bilateral axillary, perineal, sacral and gluteal regions. His complaints initiated 4 years ago. A rare extensive case of hidradenitis was treated firstly by excision of the right axillary region and reconstructed with scapular artery island flap. Same procedure was applied to the left axillary hidradenitis 2 months later. Bilateral rectangular 500cc expanders were applied to the inguinal regions and right and left expanders were inflated up to $740 \mathrm{cc}$ and $650 \mathrm{cc}$ respectively within 6 weeks. Expanders were extracted and perineal region defects were covered with advancement flaps after resection of the lesions. Sacral and gluteal regions were reconstructed with primary closure after excision. Overall treatment lasted 10 months without any complication. Axillary reconstruction of Case 4 is presented in Figure 3.

\section{Case 5:}

A 2 years old girl admitted to our clinic with a $12 \%$ burn defect covering the arm, forearm, axilla and lateral thoracic area. The thermal burn injury mostly caused deep second degree burns and necessitated surgical interventions. Arm and forearm was covered with skin grafting after extensive debridement. Axillary and lateral thoracic region was reconstructed with scapular artery island flap by minimally skeletonizing the pedicle. The aim was to prevent breast growth impairment by insetting the flap on anterior axillary line. Tip of the flap had minimal necrosis that eventually healed by secondary intention. Post-operative followups were uneventful and the patient was generally in good condition. Figure 5 presents intra-operative and post-operative images of Case 5 .

\section{DISCUSSION}

Dos Santos (9) was the first to describe the scapular flap in 1980 and Dimond and Barwick covered the axillary area by using this technique (10). Having thin and pliable skin and ease of elevation, scapular flaps seem to be advantageous in covering axillary defects.

Various indications may necessitate different approaches of reconstruction. Local flaps such as posterior arm or parascapular flaps could be applied in order to cover defects after hidradenitis suppurativa excisions. However, this may not be the issue in cases of severe burn contractures since posterior axillary fold and arm may also be involved. Toracodorsal artery perforator flap also may not be appropriate for burn contracture treatments as the parascapular area was found mostly to be affected in burns (11). 
Thus, after releasing severe burn contractures, large defects limit the options of local flaps. Scapular flap has the advantage of horizontal extension on the posterior torso away from the zone of injury.

Free DIEP flaps have also been applied in aim of hidradenitis suppurativa defect coverage of the axillary region (4). Despite being feasible, prolonged operation time and necessity of microsurgical expertise are the major drawbacks of this procedure. Also, thinning is necessary in order to position the flap in the axillary dome because DIEP flaps relatively have thick donor areas.

Hidradenitis Suppurativa and burn contractures are the most common causes of axillary defects and scapular island flap has the advantage of covering both. Skeletonizing the pedicle gives the comfort of passing the flap through the triangular space and transferring it even to the anterior axillary line defects (11). This could be accomplished without any kinking of the pedicle. Hand-held doppler investigation could be helpful in detecting the localization of the pedicle. Intra-operative transillumination is also advantageous for tracing the horizontal branch of the scapular artery. This maintains an easy skeletonizing of the pedicle.

The major disadvantage of the scapular island flap is the widening of donor site scars. Donor sites could be closed primarily up to $12 \mathrm{~cm}$ of width (12). Even though the widest of our flaps were $8 \mathrm{~cm}$ that could be closed without tension, they resulted with widening of the scars in our case series. This may be due to the high mobility of the shoulder. Wide scars are the major disadvantage of this flap. Nevertheless, it is commonly ignored after dramatic improvements of the patients.

\section{CONCLUSION}

Scapular island flaps can cover defects of the axilla created by various causes. Horizontal extension of the flap protects it from burn scar involvements of the posterior axillary line and the arm. Although widening of the resultant scar seems to be a disadvantage, it is commonly accepted by the patients. Components such as thin and pliable skin, ease of elevation and minimal complication rates, turn the scapular island flap into a workhorse flap of the axillary defect reconstruction.

Conflict of interest: Author declares that there is no conflict of interest between the authors of the article.

Financial conflict of interest: Author declares that he did not receive any financial support in this study.
Address correspondence to: Mehmet Altiparmak, Muğla Sıtkı Koçman University, Faculty of Medicine, Department of Plastic, Recontructive and Aesthetic Surgery, Muğla, Turkey.

Phone: +905302738534

E-mail:dr.maltiparmak@gmail.com

\section{REFERENCES}

1. Pearce FB, Richardson KA. Negative pressure wound therapy, staged excision and definitive closure with splitthickness skin graft for axillary hidradenitis suppurativa: A retrospective study. J Wound Care 2017;26:S36-42.

2. Alharbi M, Perignon $\mathrm{D}$, Assaf $\mathrm{N}$, et al. Application of the inner arm perforator flap in the management of axillary hidradenitis suppurativa. Ann Chir Plast Esthet 2014;59(1):29-34.

3. Sirvan SS, Demir IA, Irmak F, et al. Posterior arm perforator flap for axillary reconstruction after hidradenitis suppurativa excision. Plast Surg 2019;27(3):204-10.

4. D'Arpa S, Pignatti M, Vieni S, et al. The Thin bilateral and bipedicled DIEAP flap for axillary reconstruction in hidradenitis suppurativa. Handchirurgie Mikrochirurgie Plast Chir 2019;51(6):469-76.

5. Chen $\mathrm{HC}, \mathrm{Wu} \mathrm{KP}, \mathrm{Yen} \mathrm{Cl}$, et al. Anterolateral thigh flap for reconstruction in postburn axillary contractures. Ann Plast Surg 2017;79(2):139-44.

6. Turkaslan T, Turan A, Dayicioglu D, et al. Uses of scapular island flap in pediatric axillary burn conractures. Burns 2006;32(7):885-90.

7. Modest MC, Moore EJ, Abel KMV, et al. Scapular flap for maxillectomy defect reconstruction and preliminary results using three-dimensional modeling. Laryngoscope 2017;127(1):E8-14.

8. Chen B, Xu M, Chai J, et al. Surgical treatment of severe or moderate axillary burn scar contracture with transverse island scapular flap and expanded transverse island scapular flap in adult and pediatric patients - A clinical experience of 15 cases. Burns 2015;41(4):872-80.

9. Dos Santos L. Retalho escapular: Um novo retalho livre microcirurgico. Rev Bras Cir 1980;70(3-4):133-44.

10. Dimond $M$, Barwick W. Treatment of axillary burn scar contracture using an arterialized scapular island flap. Plast Reconstr Surg 1983;72(3):388-90.

11. Nişanci M, Er E, Işik $S$, et al. Treatment modalities for postburn axillary contractures and the versatility of the scapular flap. Burns 2002;28(2):177-80.

12. Hamilton SGL, Morrison WA. The scapular free flap. $\mathrm{Br} \mathrm{J}$ Plast Surg 1982;35(1):2-7. 